\title{
Allied health - 3009. Comparative assessment of dental caries experience, oral hygiene status, gingival health status, salivary Streptococcus mutans count and Lactabacillus count between asthmatic and non-asthmatic children aged between 5-12 years in Davangere City, Karnataka, India
}

Usha Venkatesh

From 2nd WAO International Scientific Conference (WISC 2012)

Hyderabad, India. 6-9 December 2012

\section{Background}

To assess and compare the caries experience, oral hygiene status, gingival health status, salivary Streptococcus mutans count and Lactobacillus count between asthmatic children and a healthy control group.

\section{Methods}

A cross sectional comparative study was conducted on 5-12 years old, 40 asthmatic and 62 non-asthmatic subjects in Davanagere city. Selection criteria - a) children with diagnosis of asthma as diagnosed by lung function test by the medical officer of the asthma care centre, Bapuji Hospital, Davanagere, who were currently on asthmatic medication belonging to 5-12 year age group residing in Davanagere city. b) The non-asthmatic status of selected controls was ascertained by asking certain relevant questions to the children and their parents which can elicit the presence of symptoms of asthma. Cases and controls were matched for gender, age, socio-economic status, diet and oral hygiene practices. Relevant and required information regarding demographic characteristics and asthmatic status was obtained. DMFT index and def index were used to assess the dental caries status. Oral Hygiene Simplified Index (OHI-S) and Gingival Index were used to assess the oral hygiene status and gingival status respectively. Paraffin stimulated saliva sample

\footnotetext{
Public Health Dentistry, Bapuji Dental College and Hospital, Davanagere,
} India

(c) 2013 Venkatesh; licensee BioMed Central Ltd. This is an Open Access article distributed under the terms of the Creative Commons Attribution License (http://creativecommons.org/licenses/by/2.0), which permits unrestricted use, distribution, and reproduction in any medium, provided the original work is properly cited. was collected from both asthmatic and non-asthmatic subjects for microbiological analysis.

\section{Results}

A significant association was found between asthmatic status and dental caries $(\mathrm{p}<0.05)$. There were no significant differences in gingival status and oral hygiene status between asthmatic and non-asthmatic children. The number of S.mutans colonies was significantly different between the two groups ( $94.1 \pm 60$ colonies in the study group versus $57 \pm 30.5$ colonies in the control group; $\mathrm{p}<0.001$ ).

\section{Conclusions}

Asthmatic children had higher caries experience and it increased with duration of asthma. The frequency, duration and type of medication for asthma were not found to have any significant effect. Salivary S.mutans was high in asthmatic children where as salivary Lactobacillus was similar in both the groups.

Published: 23 April 2013

\section{doi:10.1186/1939-4551-6-S1-P185}

Cite this article as: Venkatesh: Allied health - 3009. Comparative assessment of dental caries experience, oral hygiene status, gingival health status, salivary Streptococcus mutans count and Lactabacillus count between asthmatic and non-asthmatic children aged between 5-12 years in Davangere City, Karnataka, India. World Allergy Organization Journal 2013 6(Suppl 1):P185. 